\title{
Numerical Simulation of Free Convection in a Partially Heated Three-Dimensional Enclosure Filled with Ionanofluid $\left(\left[\mathrm{C}_{4} \mathrm{mim}\right]\right.$ $\left.\left[\mathbf{N T f}_{2}\right]-\mathbf{C u}\right)$
}

\author{
Said Bouchta $\mathbb{D}^{1},{ }^{1}$ M'barek Feddaoui, ${ }^{2}$ and Abdellatif Dayf ${ }^{2}{ }^{2}$ \\ ${ }^{1}$ Applied Science Faculty, Ibn Zohr University, Ait Melloul, Morocco \\ ${ }^{2}$ National School of Applied Sciences, Ibn Zohr University, Agadir, Morocco \\ Correspondence should be addressed to Said Bouchta; s.bouchta@uiz.ac.ma
}

Received 29 December 2020; Revised 21 March 2021; Accepted 16 April 2021; Published 27 April 2021

Academic Editor: Vamsi Krishna

Copyright (C) 2021 Said Bouchta et al. This is an open access article distributed under the Creative Commons Attribution License, which permits unrestricted use, distribution, and reproduction in any medium, provided the original work is properly cited.

A numerical analysis was performed to study free convection in a stationary laminar regime in a partially heated cube filled with ionanofluid. To numerically solve the dimensionless equations, we applied the finite volume method using the SIMPLEC algorithm for pressure correction. All walls are adiabatic, except for the left and right side walls which are partially heated differently. At the end of this simulation, several results are given in the form of current lines, isotherms, and variations in the Nusselt number. These results are obtained by analyzing the effect of a set of factors such as Rayleigh number, particle volume fraction, cold and source position on the dynamic and thermal fields, and heat transfer. It has been shown that the percentage of nanoparticles and high Rayleigh numbers significantly increase heat transfer by ionanofluid. Two comparisons have been made, between ionic fluid and ionanofluid at isotherms and streamlines, and between nanofluid and ionanofluid at Nusselt number, which show the advantage of using ionanofluid in heat transfer.

\section{Introduction}

The low thermal conductivity of conventional fluids used in free convection has led physicists to replace them with another, that is, with a high thermal conductivity called nanofluid. This new fluid invented by Choi and Eastman [1] is a colloidal solution composed of nanoparticles suspended in a base fluid. A summary was prepared by $\mathrm{Yu}$ and Xie [2] on the progress of the study of nanofluids, such as preparation methods, methods of assessing the stability of nanofluids, and ways to improve the stability of nanofluids, the stability mechanisms of nanofluids, and their current and future applications in various fields. Nanofluids have shown great progress in convection [3] in various applications such as heat exchangers, automotive parts, and cooling of electronic and electrical components.

Several works have been published on nanofluids. Putra et al. [4] conducted an experiment to analyze the behavior of water- $\mathrm{Al}_{2} \mathrm{O}_{3}$ and water-CuO nanofluids in a horizontal cylinder subjected to constant temperatures. Mohebbi et al. [5] studied the natural convection of a nanofluid. They analyzed the effect of the existence of a heat source and its location on the flow rate of a C-shaped enclosure. Mehryan et al. [6] numerically analyzed the free convection inside porous enclosures filled with water/Ag- $\mathrm{MgO}$ nanofluids with Darcy and LTNE conditions. The results indicate that the dissipation of $\mathrm{MgO}-\mathrm{Ag}$ in the base fluid significantly reduces heat transfer. They found that increasing the concentration of the nanoparticles significantly improves the heat transfer for the nanofluid $\mathrm{CuO}$-water. Khanafer et al. [7] have numerically processed nanofluids in free convection. Their findings show that at any Grashof number, the added nanoparticles remarkably increase the rate of heat transfer.

Other studies [8-13] have shown the effect of increasing the concentration of nanoparticles on improving heat transfer. A number of researchers studied magnetohydrodynamics (MHD). Mansour et al. [14] performed a 
numerical study of the natural convection of the nanofluid MHD in a square cavity under thermal boundary conditions. Ahmed et al. [15] digitally studied two heating systems inside triangular chambers filled with nanofluid under the Lorentz force. They showed that the thermal transfer improves with the increase in the height of the fins and also improves with the increase in the percentage of nanoparticles and the parameter heat production/absorption while the presence of magnetic force slows the movement of fluids and decreases the rate of heat transfer.

Alsabery et al. [16] studied free convection in a cavity with elastic walls; it was observed that the elastic walls affect the fluid flow and heat transfer characteristics. In the presence of a uniform magnetic field, a numerical study was carried out by Selimefendigil and Öztop [17] of the laminar flow of nanofluid on a corrugated plate. They showed that the pulsed flow improves the heat transfer rate compared to the case of a constant flow. Selimefendigil and Öztop proposed the use of nanofluid jets for cooling an isothermal surface under the influence of a rotating cylinder [18], which affects the fluid flow and heat transfer characteristics. The same researchers [19] used the same technique for cooling an isothermal surface in a partially porous medium under the impact of an inclined magnetic field. They observed that the characteristics of the magnetic field and the porous medium have significant impacts on the variation of the flux and thermal patterns for the thermal configuration.

The free convection of nanofluids in $3 \mathrm{D}$ cavities has been addressed by few researchers. Ravnik et al. [20] have analyzed the free convection of nanofluids in a cube with the boundary element method (BEM). Zhou et al. [21], using the Boltzmann method, have created a 3D model to analyze the heat transfer and flow dynamics of the mixed convection of the nanofluid water- $\mathrm{Al}_{2} \mathrm{O}_{3}$ in a cube in the existence of a magnetic field. Different parameters were considered in this study of nanofluid flow and heat transfer, such as Rayleigh, Hartmann, and Richardson numbers and volume fraction of nanoparticles. The conclusions show that a low $\mathrm{Ra}$ and the addition of particles to water can improve the heat transfer effect. However, at high Rayleigh numbers, this improvement in heat transfer may be weakened or even reversed. In addition, the findings show that the external magnetic field applied has the effect of removing the convection state of heat transfer within the enclosure.

El Moutaouakil et al. [22] studied the influence of thermal radiation on free convection of various nanofluids in a partially heated cubic cavitation. They studied the impact on the dynamic and thermal fields and also the heat transfer of several parameters, the volume fraction, the radiation components, the aspect ratio of the heated elements, and the angle of inclination of these elements $\left(0^{\circ}, 45^{\circ}\right.$, and $90^{\circ}$ ). Selimefendigil and Öztop [23] treated convective heat transfer in a $3 \mathrm{D}$ enclosure separated by a conductive partition and having an internal rotating adiabatic circular cylinder. The cavity is filled with nanofluid (carbon/water nanotubes). They analyzed the impact on the heat transfer of various parameters, Richardson number, the angular rotation velocity of the inner cylinder, the thickness, and the solid fraction $\varphi$. Atashafrooz [24] studied numerically in 3D the circulation of nanofluid in an inclined step. He showed that the nanoparticle volume fraction acts more on the temperature distribution than on the velocity distribution and increases the coefficient of friction, temperature, and Nusselt number.

A three-dimensional simulation of the mesoscopic scale of natural magnetohydrodynamic convection using the Lattice Boltzmann method has been examined by Sajjadi et al. [25]. The findings show that increasing the Hartmann number considerably weakens the heat transfer. In addition, the influence of the $\mathrm{Ha}$ increases with the improvement of the Grashof number, such as the reduction of the average number of Nusselt. Bouchta and Feddaoui [26] have also studied the effect of the presence of a magnetic field on the flow and heat transfer of a nanofluid in a three-dimensional cavity. Different parameters were considered in this study such as Rayleigh and Hartmann numbers and the volume fraction of nanoparticles. The findings show that the applied magnetic field has the influence to make the convection state of heat transfer in the cavity disappear. Al-Sayegh [27] has numerically analyzed the free convection of a carbon nanotube (CNT) nanofluid within an open trapezoidal enclosure under the action of an inclination of the outside magnetic field by the finite volume method. The analysis took into account several factors, noting the Rayleigh and Hartmann numbers, the solid fraction, and the angle of inclination of the magnetic force. It has been found that, for high values of $\mathrm{Ra}$, the heat transfer rate decreases when the Hartmann number is increased, while this heat transfer rate improves with increasing volume fraction of the nanoparticles regardless of the angle of inclination of the magnetic field.

A numerical investigation of the free convection of CNT nanofluids based on finite volumes is carried by Al-Rashed et al. [28]; they analyzed the influence of adequate factors, such as the Rayleigh number, the nanoparticles volume fraction, angle of inclination of the outer magnetic field, and the Hartmann number. They show that heat transfer improves with the addition of particles (CNT) and Rayleigh number. When Ha goes from 50 to 100, magnetic repulsion inhibits heat transfer by $50 \%$.

A new class of heat transfer fluids proposed by Ribeiro et al. [29] called ionanofluid, which is today a hot research topic, has its fascinating thermophysical properties proven by several papers [30-33].

According to the literature review, the use of nanofluids and their derivatives to improve free convection heat transfer performance is an important and interesting topic. To my knowledge, there are few studies on the numerical investigation of the impact of ionanofluid on heat transfer performance. The objective of this work is to study the flow of an ionanofluid ( $\mathrm{Cu}$ /ionic fluid) through a cube, as well as to quantify the convective exchanges. The effects of ionanofluid and Rayleigh number as well as the influence of the concentration of nanoparticles on the thermal performance of the cavity are analyzed in this study. 


\section{Mathematical Modeling}

The study geometry (Figure 1) is a three-dimensional enclosure that is full of an ionic liquid and copper nanoparticles. The side walls are partially heated according to the four cases illustrated in Figure $1\left(\mathrm{~T}_{h}>\mathrm{T}_{c}\right)$. The other walls are assumed adiabatic.

All thermophysical properties (at $300 \mathrm{~K}$ ) listed in Table 1 are considered constant.
For the modeling of the physical problem described in Figure 1, we will adopt the following simplifying hypotheses: the flow is laminar, and the fluid is incompressible and Newtonian, apart from the density that evolves according to the Boussinesq approximation of Bejan [34].

Our system of equations, in steady state, of conservation of mass and conservation of momentum and energy that governs the configuration studied in its dimensionless form is given by [23]

$$
\begin{aligned}
\frac{\partial U}{\partial X}+\frac{\partial V}{\partial Y}+\frac{\partial W}{\partial Z} & =0 \\
U\left(\frac{\partial U}{\partial X}\right)+V\left(\frac{\partial U}{\partial Y}\right)+W\left(\frac{\partial U}{\partial Z}\right) & =-\frac{\partial P}{\partial X}+\frac{\mu_{n f}}{\rho_{n f} \alpha_{f}}\left(\frac{\partial^{2} U}{\partial X^{2}}+\frac{\partial^{2} U}{\partial Y^{2}}+\frac{\partial^{2} U}{\partial Z^{2}}\right) \\
U\left(\frac{\partial V}{\partial X}\right)+V\left(\frac{\partial V}{\partial Y}\right)+W\left(\frac{\partial V}{\partial Z}\right) & =-\frac{\partial P}{\partial Y}+\frac{\mu_{n f}}{\rho_{n f} \alpha_{f}}\left(\frac{\partial^{2} V}{\partial X^{2}}+\frac{\partial^{2} V}{\partial Y^{2}}+\frac{\partial^{2} V}{\partial Z^{2}}\right) \\
U\left(\frac{\partial W}{\partial X}\right)+V\left(\frac{\partial W}{\partial Y}\right)+W\left(\frac{\partial W}{\partial Z}\right) & =-\frac{\partial P}{\partial Z}+\frac{\mu_{n f}}{\rho_{n f} \alpha_{f}}\left(\frac{\partial^{2} W}{\partial X^{2}}+\frac{\partial^{2} W}{\partial Y^{2}}+\frac{\partial^{2} W}{\partial Z^{2}}\right)+\frac{(\rho \beta)_{n f}}{\rho_{n f} \beta_{f}} \operatorname{RaPr} \theta \\
U\left(\frac{\partial \theta}{\partial X}\right)+V\left(\frac{\partial \theta}{\partial Y}\right)+W\left(\frac{\partial \theta}{\partial Z}\right) & =\frac{\alpha_{n f}}{\alpha_{f}}\left(\frac{\partial^{2} \theta}{\partial X^{2}}+\frac{\partial^{2} \theta}{\partial Y^{2}}+\frac{\partial^{2} \theta}{\partial Z^{2}}\right)
\end{aligned}
$$
are

The dimensionless parameters of the previous equations

$$
\begin{aligned}
X & =\frac{x}{H}, \\
Y & =\frac{y}{H}, \\
Z & =\frac{z}{H}, \\
U & =\frac{u H}{\alpha_{f}}, \\
V & =\frac{v H}{\alpha_{f}}, \\
W & =\frac{w H}{\alpha_{f}}, \\
P & =\frac{p H^{2}}{\rho_{n f} \alpha_{f}^{2}} \\
\theta & =\frac{T-T_{c}}{T_{h}-T_{c}}, \\
\operatorname{Ra} & =\frac{g \beta_{f}\left(T_{h}-T_{c}\right) H^{3}}{\alpha_{f} v_{f}}, \\
\operatorname{Pr} & =\frac{v_{f}}{\alpha_{f}} .
\end{aligned}
$$

Table 2 shows the thermophysical properties of ionanofluid $\left(\left[\mathrm{C}_{4} \mathrm{mim}\right]\left[\mathrm{NTf}_{2}\right]-\mathrm{Cu}\right)$.

Equations (1)-(5) obtained are solved with the following boundary conditions:

$$
\begin{aligned}
U & =V=W=0, \text { on all the walls, } \\
\theta & =0.5, \text { with } X=0 \text { and } 0<Z<0.5 \text { or } 0.5<Z<1, \\
\theta & =-0.5 \text { with } X=1 \text { and } 0<Z<0.5 \text { or } 0.5<Z<1, \\
\frac{\partial \theta}{\partial n} & =0, \text { for the others, }
\end{aligned}
$$

where $n$ denotes the normal direction to the wall.

The calculation of the average Nusselt number is based on the following relation:

$$
\begin{aligned}
& \mathrm{Nu}_{\text {avg }}=\int_{0}^{1} \int_{0.5}^{1}-\frac{k_{\text {inf }}}{k_{f}}\left(\frac{\partial \theta}{\partial X}\right)_{X=0} \mathrm{~d} Z \mathrm{~d} Y, \text { for the hot part at the top, } \\
& \mathrm{Nu}_{\text {avg }}=\int_{0}^{1} \int_{0}^{0.5}-\frac{k_{\text {inf }}}{k_{f}}\left(\frac{\partial \theta}{\partial X}\right)_{X=0} \mathrm{~d} Z \mathrm{~d} Y, \text { for the hot part at the bottom. }
\end{aligned}
$$

\section{Grid Dependency}

This numerical simulation was tested for the independence of the uniform mesh on the cubic enclosure for the bottom- 


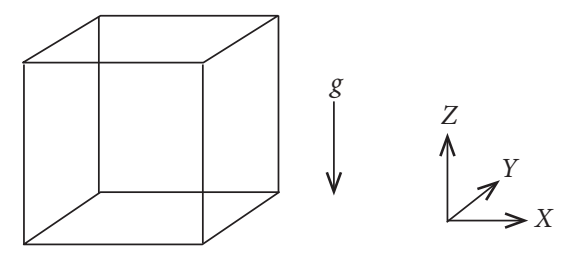

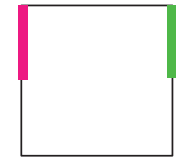

Top-top

Hot Wall

Cold Wall

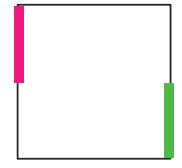

Top-bottom

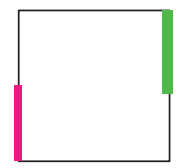

Bottom-Top

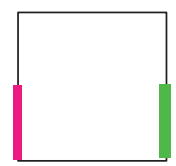

Bottom-bottom

Figure 1: Cavity geometry.

TABLe 1: Thermal and physical properties of ionanofluid with $T=300 \mathrm{~K}$.

\begin{tabular}{|c|c|c|c|}
\hline Thermophysical properties & {$\left[\mathrm{C}_{4} \mathrm{mim}\right]\left[\mathrm{NTf}_{2}\right][37]$} & $\mathrm{Cu}[36]$ & Water [36] \\
\hline $\mathrm{cp}\left(\mathrm{J} \mathrm{kg}^{-1} \cdot \mathrm{K}^{-1}\right)$ & 1353.24 & 385 & 4179 \\
\hline$\rho\left(\mathrm{kg} \mathrm{m}^{-3}\right)$ & 1436 & 8933 & 997.1 \\
\hline$k\left(\mathrm{~W} \mathrm{~m}{ }^{-1} \cdot \mathrm{K}^{-1}\right)$ & 0.1276 & 400 & 0.613 \\
\hline$\beta\left(\mathrm{K}^{-1}\right)$ & $6.692 \times 10^{-4}$ & $1.67 \times 10^{-5}$ & $21 \times 10^{-5}$ \\
\hline$\alpha\left(\mathrm{m}^{2} \cdot \mathrm{s}^{-1}\right)$ & $0.657 \times 10^{-7}$ & $1163.1 \times 10^{7}$ & $1.47 \times 10^{7}$ \\
\hline
\end{tabular}

TABLE 2: Thermal and physical properties of an ionanofluid.

\begin{tabular}{lc}
\hline Properties & Ionanofluid (11) \\
\hline Density & $\rho_{\text {inf }}=\left(1-\varphi_{p}\right) \rho_{f}+\varphi_{\rho p}$ \\
Heat capacity & $\left(\rho c_{p}\right)_{\text {inf }}=\left(1-\varphi_{p}\right)\left(\rho c_{p}\right)_{f}+\varphi\left(\rho c_{p}\right) p_{p}$ \\
Thermal expansion coefficient & $(\rho \beta)_{\text {inf }}=\left(1-\varphi_{p}\right)(\rho \beta)_{f}+\varphi(\rho \beta)_{p}$ \\
Viscosity & $\mu_{\text {inf }}=\left(\mu_{f} /\left(1-\varphi_{p}\right){ }^{2.5}\right)$ \\
Thermal conductivity & $\left(k_{\text {inf }} / k_{f}\right)=\left(k_{p}+2 k_{f}-2 \varphi_{p}\left(k_{f}-k_{p}\right) / k_{p}+2 k_{f}+\varphi_{p}\left(k_{f}-k_{p}\right)\right)$ \\
Thermal diffusivity & $\alpha_{\text {inf }}=\left(k_{\text {inf }} /\left(\rho c_{p}\right)_{\text {inf }}\right)$ \\
\hline
\end{tabular}

bottom case with two Rayleigh values $\left(\mathrm{Ra}=10^{5}, 10^{6}\right)$ and $\varphi=0.05$. The well-known Richardson extrapolation technique was used [38-40]. The relation is given by $I_{\text {ext }}=I_{M 3}-$ $\left[\left(\left(I_{M 2}-I_{M 3}\right) /\left(r^{p}-1\right)\right)\right]$, where the ratio of the spacing between the coarse and fine grid is represented by $r=1.5$ and the accuracy of the extrapolation by $p=2$.

The evolution of the mean Nusselt number with the refinement of the grid for Rayleigh values $\mathrm{Ra}=10^{5}$ and $\mathrm{Ra}=10^{6}$ has been given in Table 3 . The "percentage numerical error" Error $=\left|\left(I_{M 2}-I_{\text {ext }}\right) / I_{\text {ext }}\right| \times 100 \%$ for the two average Nusselt numbers is also given in Table 3. The results are seen to be in good agreement between grid sizes $60^{3}$ and $90^{3}$. In addition, the percentage error decreases as the grid size increases. Therefore, grid size $60^{3}$ was chosen in this work for good accuracy and computing time.

\section{Numerical Method}

We use the finite volume method to discretize the equations of the mathematical model. The obtained equations are solved by the usual iterative method TDMA [35]. The iterative process takes into account the pressure correction by implementing the SIMPLEC algorithm [41] and reaches convergence when the variation of the dependent variables $(U, V, W, P$, or $\theta)$ is no longer significant. A test for stopping the iterative process at convergence is established at each stretch according to the following criterion:

$$
\sum_{i, j, k=1}^{i \max , j \max , k \max } \frac{\left|\varnothing_{i, j, k}^{n+1}-\varnothing_{i, j, k}^{n}\right|}{\left|\varnothing_{i, j, k}^{n}\right|} \leq 10^{-5},
$$


TABLE 3: Grid refinement and numerical accuracy study.

\begin{tabular}{lcccccc}
\hline & \multicolumn{3}{c}{$\mathrm{Ra}=10^{5}$} & & & $\mathrm{Ra}=10^{6}$ \\
& $\mathrm{M} 1$ & $\mathrm{M} 2$ & $\mathrm{M} 3$ & $\mathrm{M} 1$ & $\mathrm{M} 2$ & $\mathrm{M} 3$ \\
& $40^{3}$ & $60^{3}$ & $90^{3}$ & $40^{3}$ & $60^{3}$ & $90^{3}$ \\
\hline$I$ & 3.1 & 3.158 & 3.161 & 6.108 & 6.174 & 6.179 \\
$I_{\text {ext }}$ & & 3.1634 & & & 6.183 & \\
Error \% & 2.004 & 0.171 & 0.076 & 1.213 & 0.146 & 0.065 \\
\hline
\end{tabular}

where $\varnothing$ is one of the field variables $(U, V, W, T$, and $P)$ and $i$, $j$, and $k$ are the grid positions. $n$ represents the time step number.

To verify the numerical program, the results obtained are confronted with the results already available in the literature. The first comparison is a three-dimensional numerical simulation of free convection of air and water $(\operatorname{Pr}=0.71)$ at Rayleigh number values varying from $10^{3}$ to $10^{6}$. Table 4 shows comparisons between our results and those of the literature. After consultation, we see that our numerical results are fully consistent with those of the reference.

The second test is still free convection in a three-dimensional cavity but with a $\mathrm{Cu}$-water nanofluid. Our results are compared with those of Ravnik et al. [20]. Figure 2 shows that there is a very clear agreement between the average number of Nusselt obtained by this simulation and that obtained by Ravnik et al. [20].

\section{Results}

A numerical analysis was realized using a finite volume method to analyze the heat transfer by free convection and fluid flow in a cubic cavity, using $\left[\mathrm{C}_{4} \mathrm{mim}\right]\left[\mathrm{NTf}_{2}\right]-\mathrm{Cu}$ ionanofluid. The isotherms, streamlines, and variation of the average Nusselt number are shown for the four study cases and with different values of $\operatorname{Ra}\left(10^{3}\right.$ to $\left.10^{6}\right)$, and $\varphi(0$ to 0.05$)$.

Figure 3 illustrates the 3D distribution of the temperature in the cube for two Rayleigh numbers $10^{3}$ and $10^{6}$. The fluid moves from the hot wall to the cold wall so that the rate of heat transfer is continuously maintained in the cube. At $\mathrm{Ra}=10^{6}$, the thermal field is marked by strong gradients on the active parts, which means that the heat transfer is large by convection.

In order to have a better view of the temperature profile within the cube, and for reasons of symmetry, the plane $Y=0.5$ was considered as the study plane to represent the isotherms and current lines (Figures 4 and 5 ) with $\mathrm{Ra}=10^{3}$ and $10^{6}$ for the cases of an ionic and ionanofluid liquid of $\varphi=5 \%$.

Figures 4 and 5 illustrate the structures of the isotherms and streamlines for the four case studies with $\mathrm{Ra}=10^{3}$ and $10^{6}$. Figures are given for ionic fluid $(\varphi=0)$ and ionanofluid $(\varphi=0.05)$. It is noted that for low Rayleigh numbers $\mathrm{Ra}=10^{3}$, where viscous forces are more dominant than buoyancy forces and diffusion is the main mode of heat transfer, cells are formed occupying the entire cavity with the nucleus located in the center and rotating clockwise. It should also be noted that for a lower Rayleigh number, the current lines of the ionic liquid and the ionanofluid are almost identical. The temperature field is vertically
TABLE 4: Comparison of our Nusselt number values with Ravnik et al. [20].

\begin{tabular}{ccccc}
\hline \multirow{2}{*}{ Ra } & Air & \multicolumn{2}{c}{ Water } \\
& Ravnik et al. [20] & Present & Ravnik et al. [20] & Present \\
\hline $10^{3}$ & 1.071 & 1.0607 & 1.071 & 1.0639 \\
$10^{4}$ & 2.0564 & 2.0464 & 2.078 & 2.0583 \\
$10^{5}$ & 4.3432 & 4.2979 & 4.51 & 4.5237 \\
$10^{6}$ & 8.6792 & 8.6461 & 9.032 & 9.3897 \\
\hline
\end{tabular}

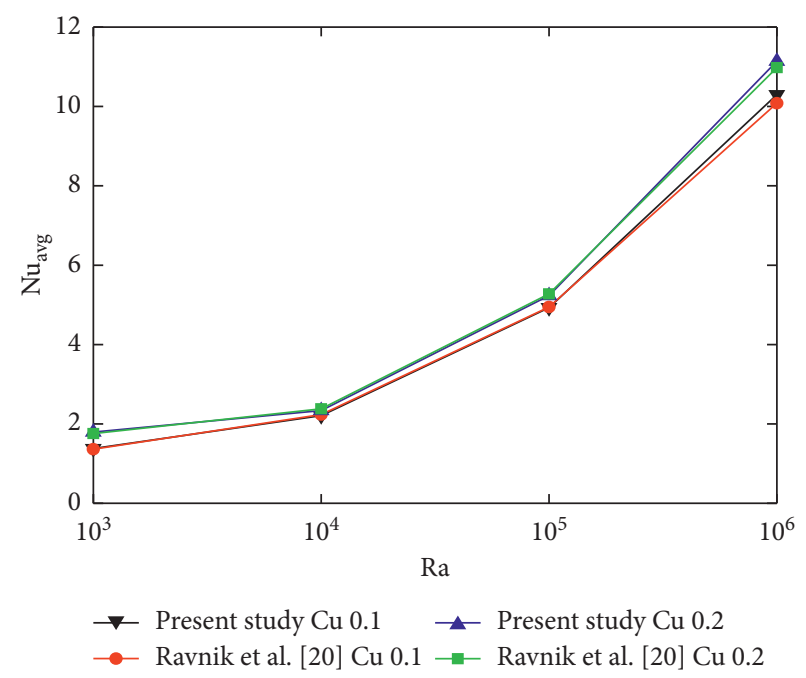

FIgURE 2: Test of our results of $\mathrm{Nu}_{\text {avg }}$ with results of Ravnik et al. [20] for $\mathrm{Cu}$-water nanofluid.

stratified, and the thermal gradients are low near the active parts. As the Rayleigh number increases $\mathrm{Ra}=10^{6}$, the intensity of recirculation in the enclosure increases and the streamlines become distorted. The thermal boundary layers become thinner and the isotherms stratify horizontally in the cavity. It is concluded that with increasing Rayleigh number, the temperature gradients become more important near the heated part of the left wall, and the intensity of the ionanofluid flow $\left(\left[\mathrm{C}_{4} \mathrm{mim}\right]\left[\mathrm{NTf}_{2}\right] / \mathrm{Cu}\right)$ becomes stronger compared to that of the pure fluid $\left(\left[\mathrm{C}_{4} \mathrm{mim}\right]\left[\mathrm{NTf}_{2}\right]\right)$.

Comparing the four case studies, it is clear that the ionic liquid and the ionanofluid behave in the same way regardless of the Rayleigh value.

Figure 6 shows the isosurfaces of ionanofluid $\left(\left[\mathrm{C}_{4} \mathrm{mim}\right]\right.$ $\left.\left[\mathrm{NTf}_{2}\right]\right)$ in $3 \mathrm{D}$ with two Rayleigh numbers $\mathrm{Ra}=10^{3}$ and $\mathrm{Ra}=10^{6}$ and a volume fraction $\varphi=5 \%$. We notice that the shape of the isosurfaces highlights the change of the heat transfer mode when the Rayleigh number increases. Indeed, for $\mathrm{Ra}=10^{3}$, the isosurfaces are almost vertical due to the dominance of the conduction mode in heat transfer. With increasing Rayleigh, the dominance of heat transfer shifts from conduction to convection. For $\mathrm{Ra}=10^{6}$, the isosurfaces are marked by an almost horizontal stratification within the cube. Figure 6 also shows that the increase in Rayleigh number naturally leads to an increase in the energy supplied to the system. The result is an increase in the convective effect and heat transfer that increases with Ra. 


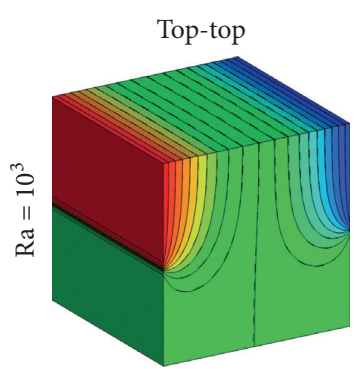

(a)

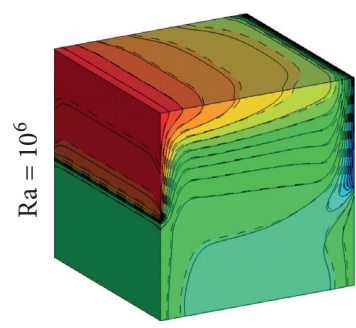

(e)

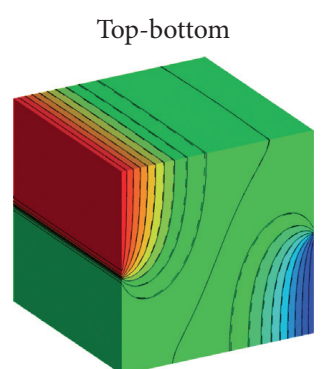

(b)

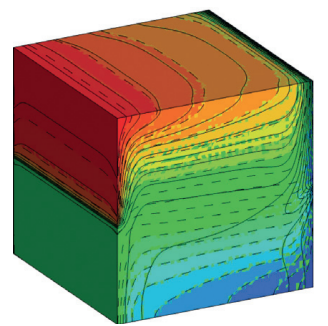

(f)

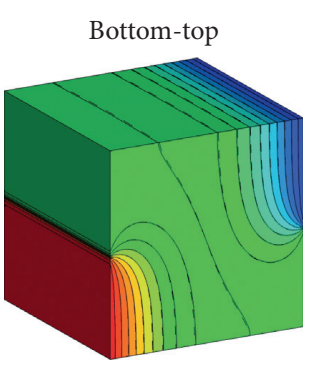

(c)

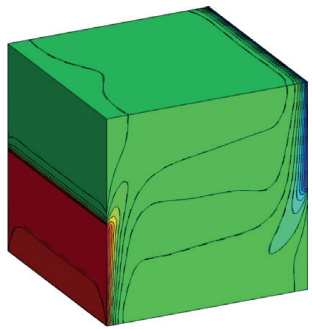

(g)

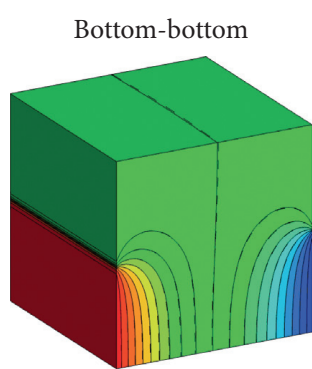

(d)

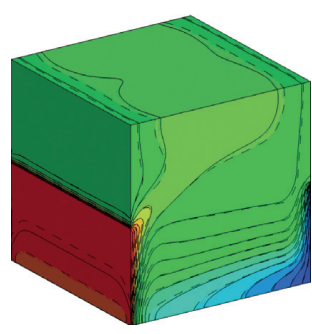

(h)

FIgURE 3: Isotherms in 3D with $\varphi=0$ (- - -) and $\varphi=0.05$ (—).

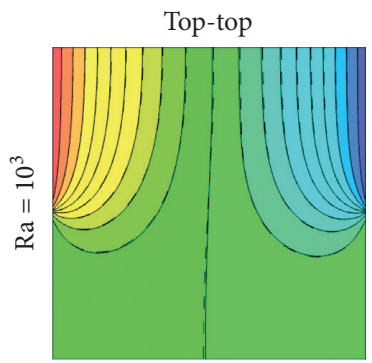

(a)

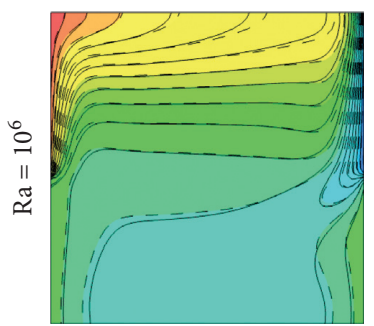

(e)
Top-bottom

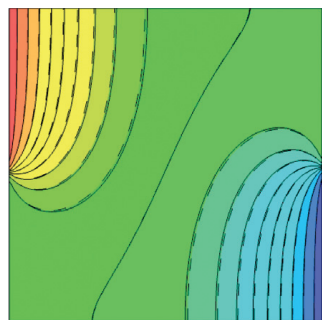

(b)

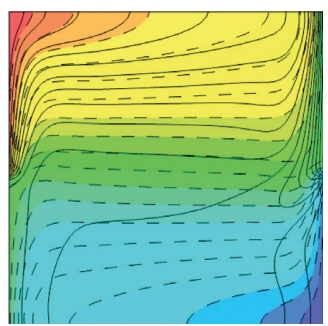

(f)

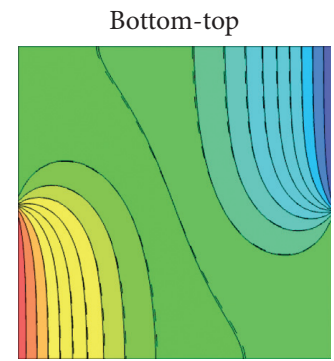

(c)

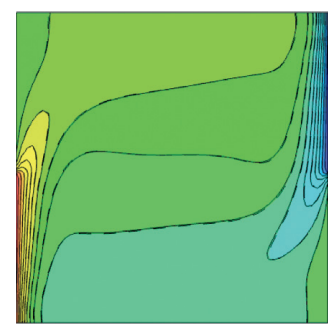

(g)
Bottom-bottom

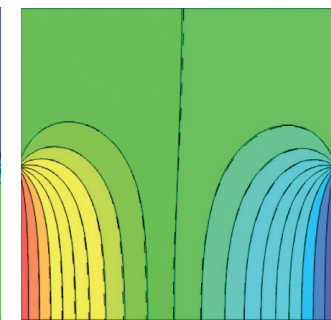

(d)

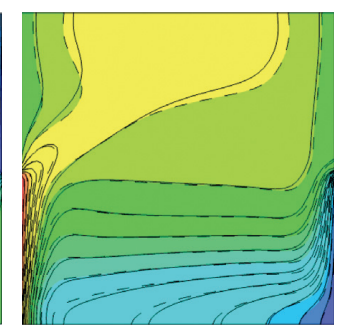

(h)

Figure 4: Isotherms in the $(X, Z)$ plane with $\varphi=0(---)$ and $\varphi=0.05$

The evolution of the average Nusselt number of ionanofluid for the four cases as a function of the Rayleigh number (Ra from $10^{3}$ to $10^{6}$ ) and the volume fraction of nanoparticles ( $\varphi$ from 0 to 5\%) is illustrated in Figure 7. We can observe that the average number of Nusselt increases as the number of Rayleigh increases. Similarly, the $\mathrm{Nu}_{\text {avg }}$ increases with the increasing percentage of nanoparticles for all Rayleigh numbers. This is due to the increased conductivity of the ionanofluid $\left[\mathrm{C}_{4} \mathrm{mim}\right]\left[\mathrm{NTf}_{2}\right]-\mathrm{Cu}$ which increases the heat transfer through the active parts of the walls. According to Figure 7, we notice that the bottom-bottom case represents the best $\mathrm{Nu}_{\mathrm{avg}}$ values, which is the best heat transfer situation.
The variation in the number of local Nusselt along the warm part for the four case studies is shown in Figure 8, with $\varphi=5 \%$ and $\mathrm{Ra}=10^{5}$. For the top-top and top-bottom cases, the values of the local Nusselt number are higher at the beginning of the heating (near the warm part at the level of the left vertical wall) and lower at the top of the cavity. The figure shows again that the highest values of the local Nusselt number are relative to the top-top case.

For the bottom-top and bottom-bottom cases, the local Nusselt number values start to drop from the beginning of the heating and increase again to reach a maximum value in the middle of the cavity. The figure also shows that the 


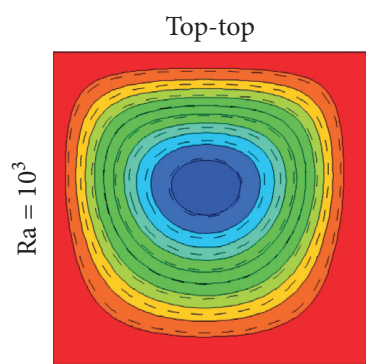

$|\psi|_{\max }=0.5$

(a)

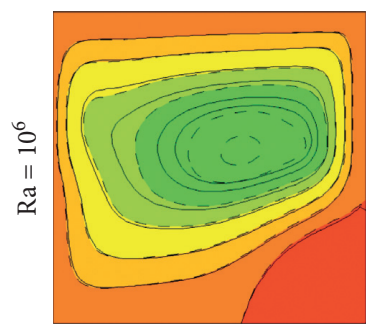

$|\psi|_{\max }=0.45$

(e)

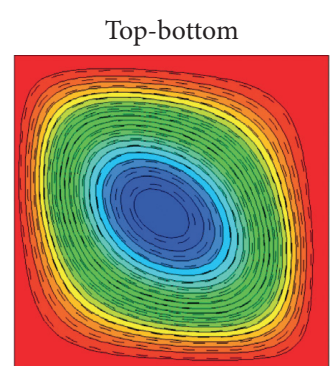

$|\psi|_{\max }=0.42$

(b)

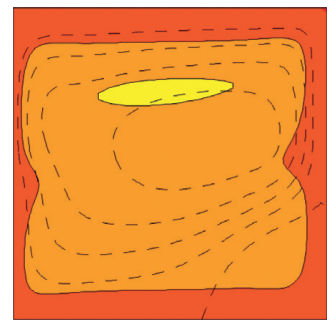

$|\psi|_{\max }=60$

(f)

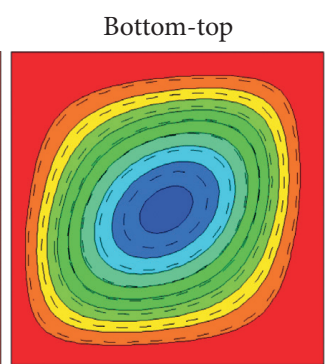

$|\psi|_{\max }=0.45$

(c)

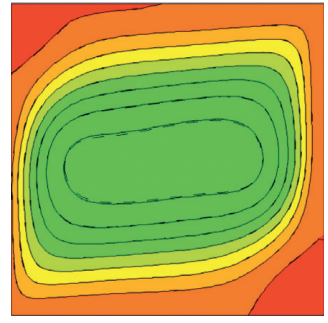

$|\psi|_{\max }=75$

(g)

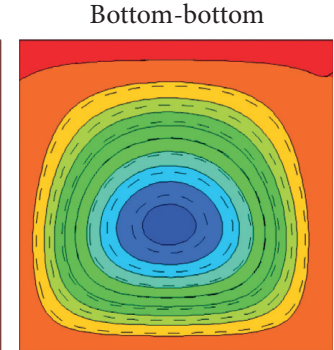

$|\psi|_{\max }=0.45$

(d)

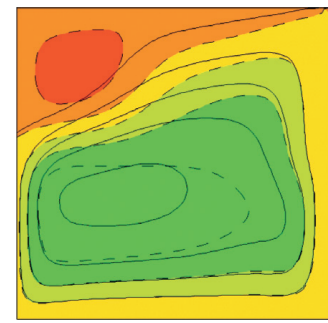

$|\psi|_{\max }=55$

(h)

Figure 5: Streamlines in the $(X, Z)$ plane with $\varphi=0(---)$ and $\varphi=0.05$

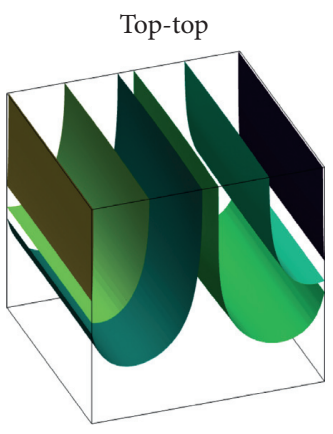

(a)

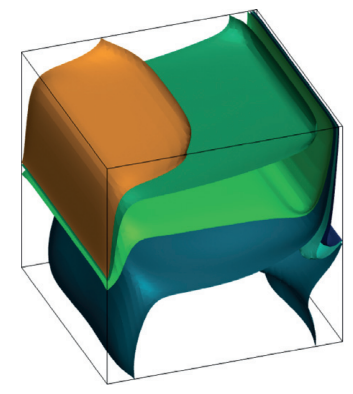

(e)

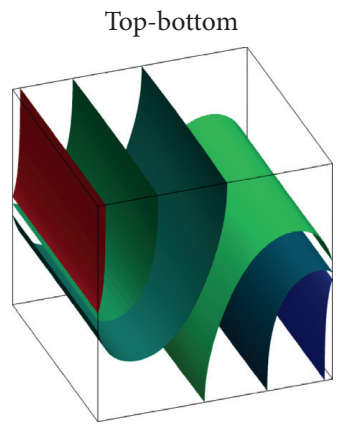

(b)

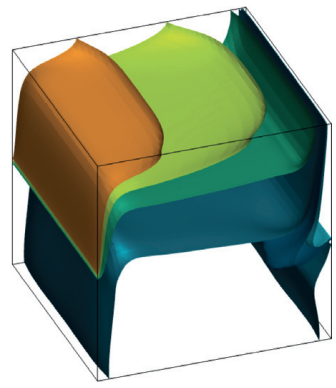

(f)

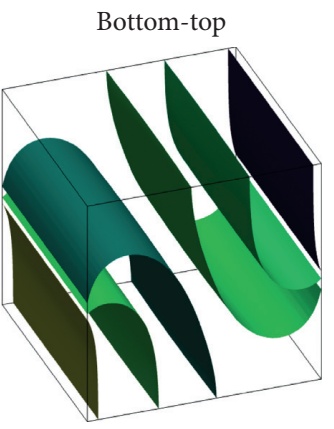

(c)

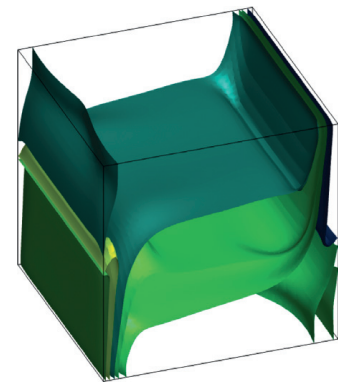

(g)

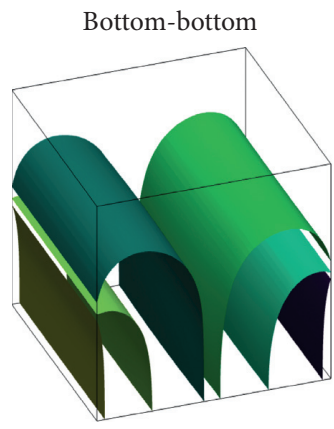

(d)

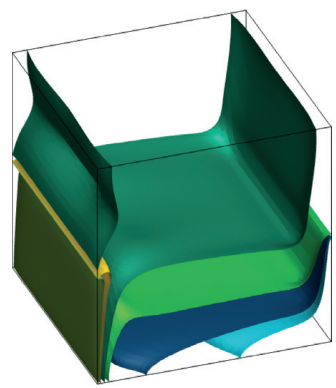

(h)

Figure 6: Temperature isosurfaces of ionanofluid $(\varphi=5 \%)$ for $\mathrm{Ra}=10^{3}$ and $\mathrm{Ra}=10^{6}$.

highest values of the local Nusselt number are relative to the bottom-bottom case.

A comparison of the variation of the average Nusselt number as a function of the volume fraction of nanoparticles between ionanofluid $\left(\left[\mathrm{C}_{4} \mathrm{mim}\right]\left[\mathrm{NTf}_{2}\right]-\mathrm{Cu}\right)$ and nanofluid (water- $\left.\mathrm{Cu}\right)$ is shown in Figure 9. The curves are given for the bottom-bottom configuration since this is the one that gives the best $\mathrm{Nu}_{\mathrm{avg}}$ values. It can be seen that the number of the mean Nusselt increases with the volume fraction $\varphi$ and that heat transfer is favored for the ionanofluid over the nanofluid. This result is due to the increased conductivity of the ionanofluid compared to the nanofluid, which improves the heat transfer to the cavity. 


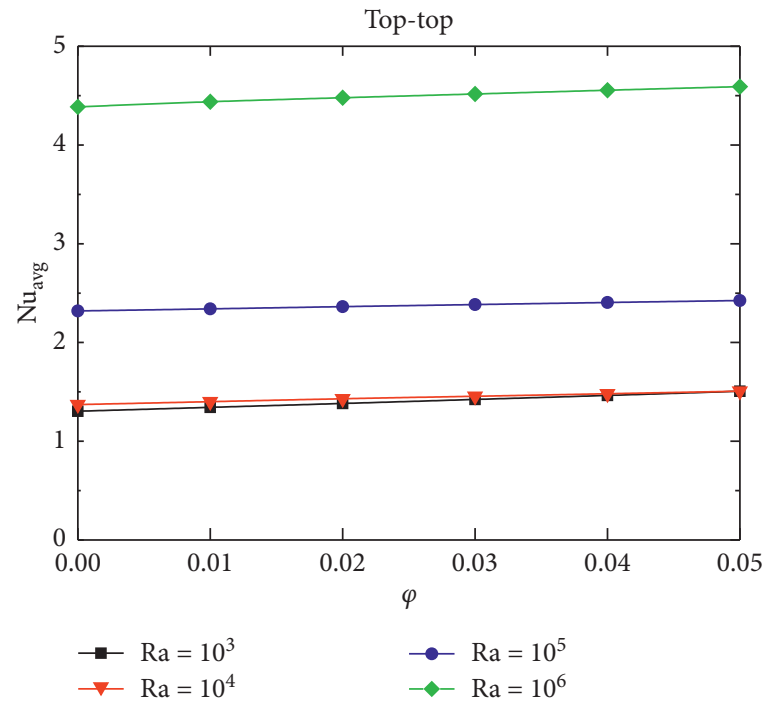

(a)

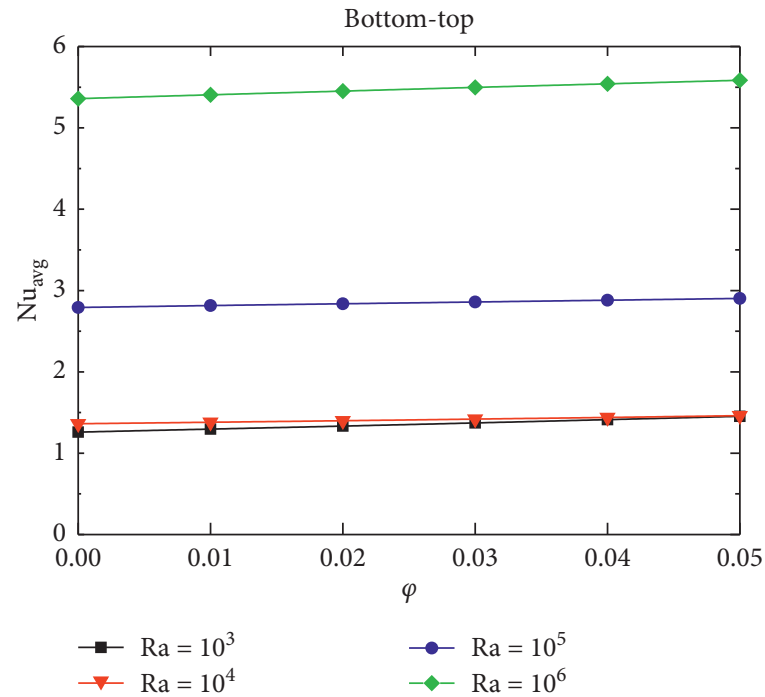

(c)

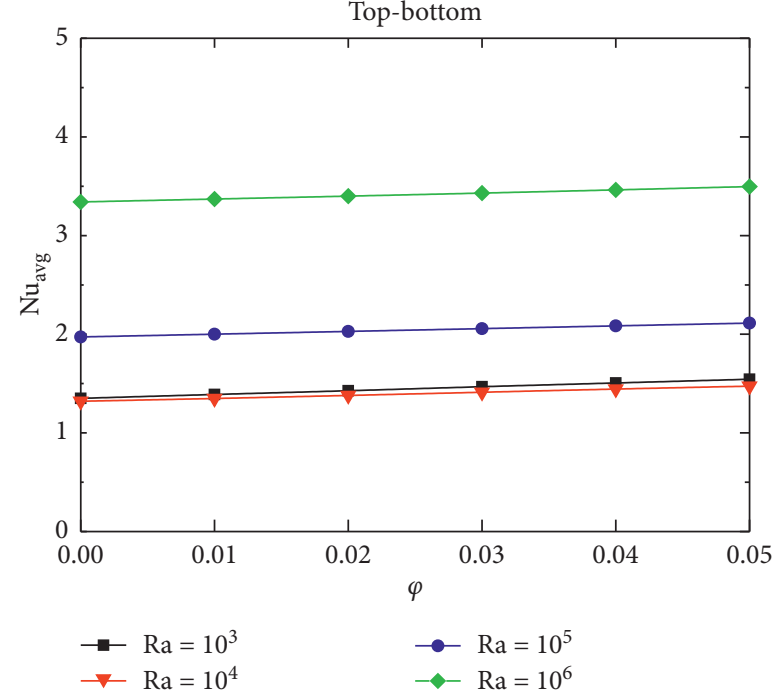

(b)

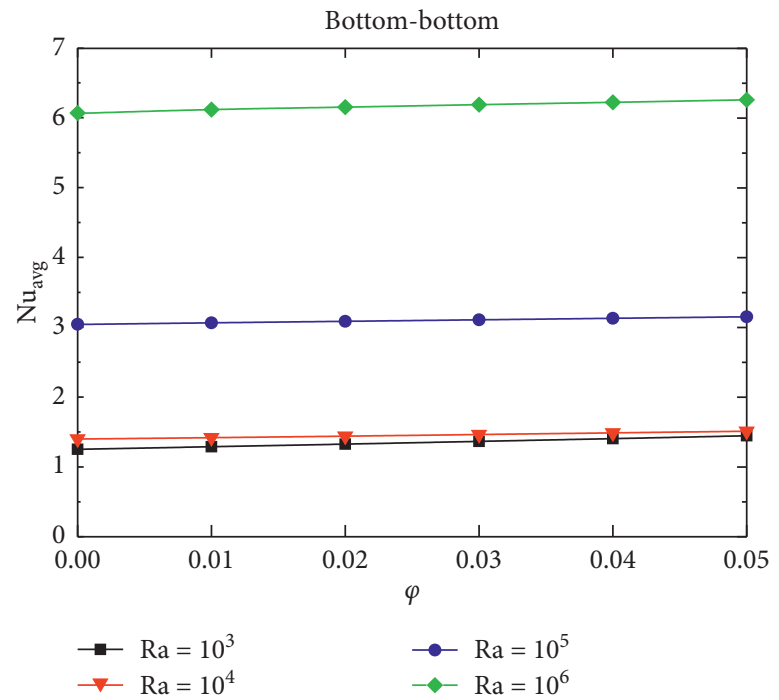

(d)

FIgURE 7: Evolution of the $\mathrm{Nu}_{\text {avg }}$ as a function of $\mathrm{Ra}$ and $\varphi$.

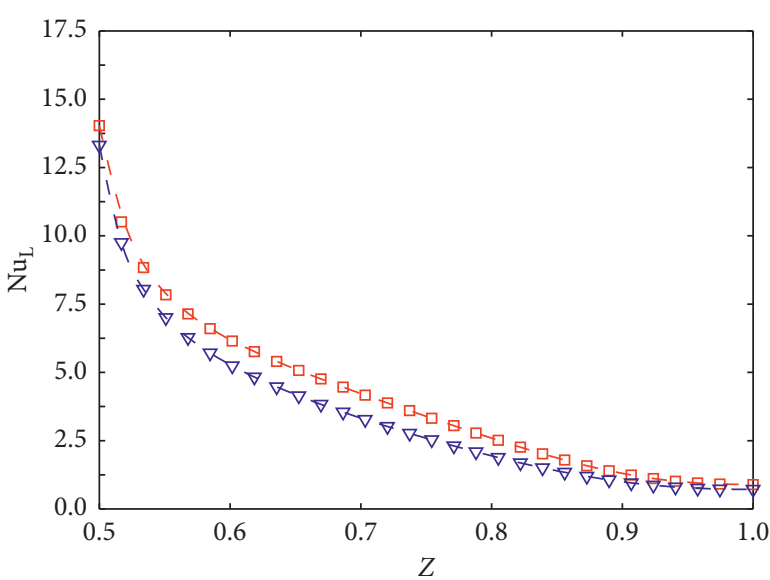

$-\square-$ Top-top

$-\nabla-$ Top-bottom

(a)

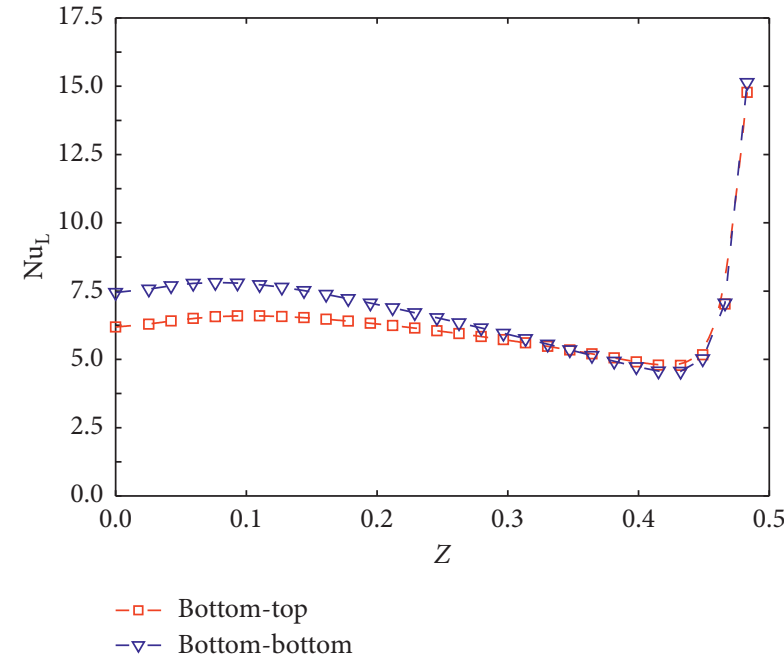

(b)

Figure 8: Evolution of the number of local Nusselt along the heated part for $\varphi=5 \%$, and $\mathrm{Ra}=10^{5}$. 


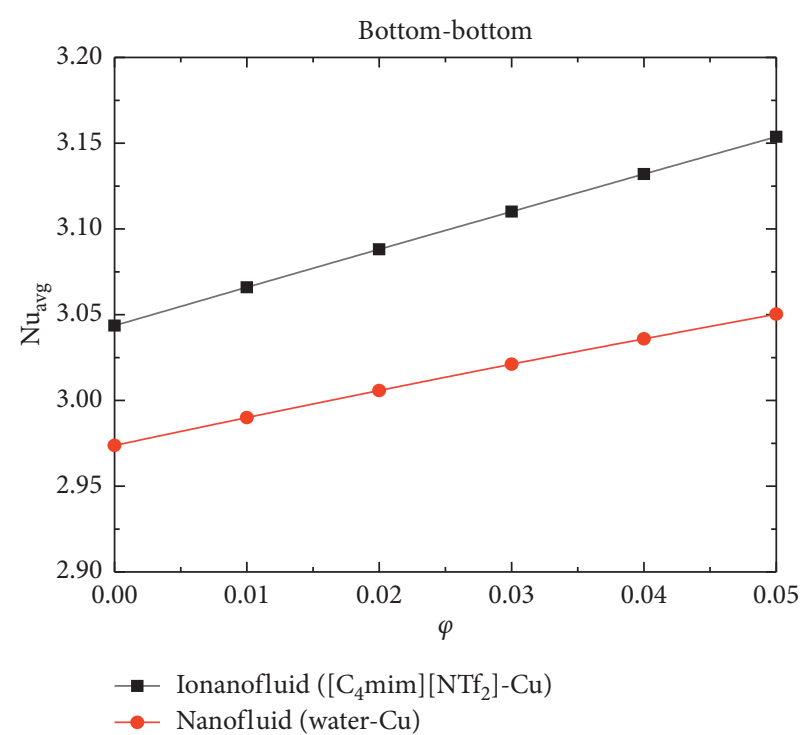

FIGURE 9: Evolution of the $\mathrm{Nu}_{\text {avg }}$ for the bottom-bottom case as a function of $\varphi$, with $\mathrm{Ra}=10^{5}$.

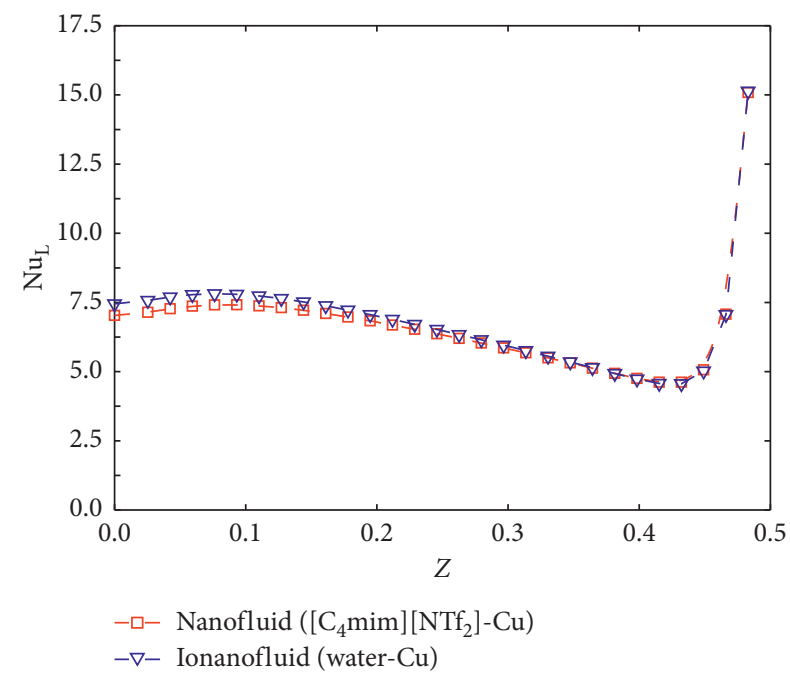

Figure 10: Evolution of the $\mathrm{Nu}_{\text {avg }}$ along the heated part for the bottom-bottom case, with $\varphi=5 \%$ and $\mathrm{Ra}=10^{5}$.

The comparison of the variations in the number of local Nusselt along the warm part of the nanofluid and ionanofluid for the bottom-bottom case is shown in Figure 10, with $\varphi=5 \%$ and $\mathrm{Ra}=10^{5}$. The figure shows that the highest values of the local Nusselt number are relative to the ionanofluid, while the lowest values of the local Nusselt number are relative to the nanofluid.

\section{Conclusions}

In this work, the free convection of ionanofluid in a partially heated cubic enclosure is studied numerically. We compared the dynamic, thermal, and thermal fields of ionanofluid to those of the pure ionic liquid, and then we analyzed the effect of relevant factors such as Rayleigh number, volume fraction, and also the position of the hot and cold plate. And finally, we made a comparison of the heat transfer between the nanofluid and the ionanofluid in terms of the average Nusselt number.

Based on the results of this analysis, the following conclusions are drawn:

(i) The addition of nanoparticles to the ionic fluid improves the thermal properties of the fluid

(ii) The average Nusselt number increases as the volume fraction of nanomaterials increases

(iii) The average Nusselt number increases with the increase in Rayleigh number

(iv) Heat transfer is improved by the use of an ionanofluid compared to pure ionic fluid

(v) The bottom-bottom case gives the highest Nusselt numbers compared to the other cases and subsequently the best heat transfer

(vi) Heat transfer is improved by the use of ionanofluid compared to nanofluid

This work can be extended by further studies to better understand the phenomenon of natural convection in a cubic cavity filled with ionanofluid; for this, we suggest the following:

(i) The influence of the shape and size of nanoparticles

(ii) The effect of Brownian motion and thermophoresis

(iii) Hydromagnetic study

\section{Glossary}

$C_{p}: \quad$ Specific heat, $\mathrm{J} \cdot \mathrm{kg}^{-1} \cdot \mathrm{K}^{-1}$

$g: \quad$ Gravitational acceleration, $\mathrm{m} \cdot \mathrm{s}^{-2}$

$h$ : $\quad$ Local heat transfer coefficient, $\mathrm{W} \cdot \mathrm{m}^{-2} \cdot \mathrm{K}^{-1}$

$H$ : $\quad$ Width of the enclosure, $\mathrm{m}$

$k$ : $\quad$ Thermal conductivity, $\mathrm{W} \cdot \mathrm{m}^{-1} \cdot \mathrm{K}^{-1}$

Nu: $\quad$ Nusselt number

$\mathrm{Nu}_{\text {avg }}: \quad$ Nusselt number average

$\mathrm{Nu}_{\mathrm{L}}: \quad$ Nusselt number local

P: $\quad$ Pressure, $\mathrm{Pa}$

Pr: $\quad$ Prandtl number

Ra: $\quad$ Rayleigh number

T: $\quad$ Dimensional temperature, ${ }^{\circ} \mathrm{C}$

$u, v, w$ : Dimensional velocity components, $\mathrm{m} \mathrm{s}^{-1}$

$U, V, W$ : Dimensionless velocity components

$x, y, z: \quad$ Dimensional coordinates, $\mathrm{m}$

$X, Y, Z$ : Dimensionless coordinates $X=(x / H)$,

$$
Y=(y / H), Z=(z / H)
$$

Greek symbols

$\alpha$ : Thermal diffusivity, $\mathrm{m}^{2} \cdot \mathrm{s}^{-1}$

$\beta$ : Thermal expansion coefficient, $\mathrm{K}^{-1}$

$\varnothing$ : Independent variable

$\mu$ : Dynamic viscosity, $\mathrm{Pa} \cdot \mathrm{s}$

$\nu$ : Kinematic viscosity, $\mathrm{m}^{2} \cdot \mathrm{s}^{-1}$

$\theta$ : Dimensionless temperature, $\theta=\left(\mathrm{T}-\mathrm{T}_{c}\right) /\left(\mathrm{T}_{h}-\mathrm{T}_{c}\right)$

$\psi$ : Stream function

$\rho$ : Density, $\mathrm{kg} \cdot \mathrm{m}^{-3}$

$\varphi$ : Solid volume fraction 


\author{
Subscripts \\ avg: Average \\ c: Cold \\ $f$ : $\quad$ Base fluid \\ $h$ : Hot \\ inf: Ionanofluid \\ nf: Nanofluid \\ p: $\quad$ Particle.
}

\section{Data Availability}

The data used to support the findings of this study are included within the article.

\section{Conflicts of Interest}

The authors declare that they have no conflicts of interest.

\section{References}

[1] S. U. S. Choi and J. A. Eastman, "Enhancing thermal conductivity of fluids with nanoparticles," Dev Appl Non Newtonian Flows, vol. 66, pp. 99-106, 1995.

[2] W. Yu and H. Xie, "A review on nanofluids: preparation, stability mechanisms, and applications," Journal of Nanomaterials, vol. 2012, Article ID 435873, 17 pages, 2012.

[3] Y. Yang, Z. G. Zhang, E. A. Grulke, W. B. Anderson, and $\mathrm{G}$. $\mathrm{Wu}$, "Heat transfer properties of nanoparticle-in-fluid dispersions (nanofluids) in laminar flowfluid dispersions (nanofluids) in laminar flow," International Journal of Heat and Mass Transfer, vol. 48, no. 6, pp. 1107-1116, 2005.

[4] N. Putra, W. Roetzel, and S. K. Das, "Natural convection of nano-fluids," Heat and Mass Transfer, vol. 39, no. 8-9, pp. 775-784, 2003.

[5] R. Mohebbi, M. Izadi, and A. J. Chamkha, "Heat source location and natural convection in a C-shaped enclosure saturated by a nanofluid," Physics of Fluids, vol. 29, Article ID 122009, 2017.

[6] S. A. M. Mehryan, M. Ghalambaz, A. J. Chamkha, and M. Izadi, "Numerical study on natural convection of Ag-MgO hybrid/water nanofluid inside a porous enclosure: a local thermal non-equilibrium model," Powder Technology, vol. 367, pp. 443-455, 2020.

[7] K. Khanafer, K. Vafai, and M. Lightstone, "Buoyancy-driven heat transfer enhancement in a two-dimensional enclosure utilizing nanofluids," International Journal of Heat and Mass Transfer, vol. 46, no. 19, pp. 3639-3653, 2003.

[8] R.-Y. Jou and S.-C. Tzeng, "Numerical research of nature convective heat transfer enhancement filled with nanofluids in rectangular enclosures," International Communications in Heat and Mass Transfer, vol. 33, no. 6, pp. 727-736, 2006.

[9] K. S. Hwang, L. Ji-Hwan, and S. P. Jang, "Buoyancy driven heat transfer of water-based $\mathrm{Al} 2 \mathrm{O} 3$ nanofluids in a rectangular cavity," International Journal of Heat and Mass Transfer, vol. 50, no. 19-20, pp. 4003-4010, 2007.

[10] C. J. Ho, M. W. Chen, and Z. W. Li, "Numerical simulation of natural convection of nanofluid in a square enclosure: effects due to uncertainties of viscosity and thermal conductivity," International Journal of Heat and Mass Transfer, vol. 51, no. 17-18, pp. 4506-4516, 2008.

[11] E. Abu-Nada and H. F. Oztop, "Effects of inclination angle on natural convection in enclosures filled with $\mathrm{Cu}$-water nanofluid," International Journal of Heat and Fluid Flow, vol. 30, no. 4, pp. 669-678, 2009.

[12] S. Bouchta, M. Feddaoui, and H. El Ihssini, "Natural convection in a square cavity containing a nanofluid and a partially-heated square block at the centre," American Journal of Heat and Mass Transfer, vol. 4, no. 1, pp. 40-52, 2017.

[13] A. Boutra, K. Ragui, N. Labsi, and Y. Benkahla, "Free convection enhancement within a nanofluid' filled enclosure with square heaters," International Journal of Heat and Technology, vol. 35, no. 3, pp. 447-458, 2017.

[14] M. A. Mansour, S. E. Ahmed, and A. M. Rashad, "MHD natural convection in a square enclosure using nanofluid with the influence of thermal boundary conditions," Journal of Applied Fluid Mechanics, vol. 9, no. 7, pp. 2515-2525, 2016.

[15] S. E. Ahmed, M. A. Mansour, A. M. Rashad, and T. Salah, "MHD natural convection from two heating modes in fined triangular enclosures filled with porous media using nanofluids," Journal of Thermal Analysis and Calorimetry, vol. 139, no. 5, pp. 3133-3149, 2020.

[16] A. I. Alsabery, F. Selimefendigil, I. Hashim, A. J. Chamkha, and M. Ghalambaz, "Fluid-structure interaction analysis of entropy generation and mixed convection inside a cavity with flexible right wall and heated rotating cylinder," International Journal of Heat and Mass Transfer, vol. 140, pp. 331-345, 2019.

[17] F. Selimefendigil and H. F. Öztop, "MHD Pulsating forced convection of nanofluid over parallel plates with blocks in a channel," International Journal of Mechanical Sciences, vol. 157, no. 158, pp. 726-740, 2019.

[18] F. Selimefendigil and H. F. Öztop, "Analysis and predictive modeling of nanofluid-jet impingement cooling of an isothermal surface under the influence of a rotating cylinder," International Journal of Heat and Mass Transfer, vol. 121, pp. 233-245, 2018.

[19] F. Selimefendigil and H. F. Öztop, "Nanojet impingement cooling of an isothermal surface in a partially porous medium under the impact of an inclined magnetic field," Journal of Thermal Analysis and Calorimetry, vol. 141, no. 5, pp. 1875$1888,2020$.

[20] J. Ravnik, L. Škerget, and M. Hriberšek, "Analysis of threedimensional natural convection of nanofluids by BEM," Engineering Analysis with Boundary Elements, vol. 34, no. 12, pp. 1018-1030, 2010.

[21] W. Zhou, Y. Yan, Y. Xie, and B. Liu, "Three dimensional lattice Boltzmann simulation for mixed convection of nanofluids in the presence of magnetic fieldfluids in the presence of magnetic field," International Communications in Heat and Mass Transfer, vol. 80, pp. 1-9, 2017.

[22] L. El Moutaouakil, M. Boukendil, Z. Zrikem, and A. Abdelbaki, "Natural Convection and thermal radiation influence on nanofluids in a cubical cavity," International Journal of Heat and Technology, vol. 38, no. 1, pp. 59-68, 2020.

[23] F. Selimefendigil and H. F. Öztop, "Conjugate mixed convection of nanofluid in a cubic enclosure separated with a conductive plate and having an inner rotating cylinder," International Journal of Heat and Mass Transfer, vol. 139, pp. 1000-1017, 2019.

[24] M. Atashafrooz, "Effects of Ag-water nanofluid on hydrodynamics and thermal behaviors of three-dimensional separated step flow," Alexandria Engineering Journal, vol. 57, no. 4, pp. 4277-4285, 2018.

[25] H. Sajjadi, A. Amiri Delouei, M. Sheikholeslami, M. Atashafrooz, and S. Succi, "Simulation of three dimensional MHD natural convection using double MRT lattice 
Boltzmann method," Physica A: Statistical Mechanics and Its Applications, vol. 515, pp. 474-496, 2019.

[26] S. Bouchta and M. Feddaoui, "Numerical simulation of free convection in a three-dimensional enclosure full of nanofluid with the existence a magnetic field," European Journal of Electrical Engineering, vol. 22, no. 6, pp. 405-411, 2020.

[27] R. Al-Sayegh, "Influence of external magnetic field inclination on three-dimensional buoyancy-driven convection in an open trapezoidal cavity filled with CNT-Water nanofluid," International Journal of Mechanical Sciences, vol. 148, pp. 756-765, 2018.

[28] A. A. A. A. Al-Rashed, K. Kalidasan, L. Kolsi et al., "Threedimensional investigation of the effects of external magnetic field inclination on laminar natural convection heat transfer in CNT-water nanofluid filled cavity," Journal of Molecular Liquids, vol. 252, pp. 454-468, 2018.

[29] A. P. C. Ribeiro, M. J. V. Lourenco, and C. A. Nieto de Castro, "Thermal Conductivity of Ionanofluids," in Proceedings of the 17th Symposium on Thermophysical Properties, Boulder, Colorado, June 2009.

[30] C. A. Nieto de Castro, M. J. V. Lourenço, A. P. C. Ribeiro et al., "Thermal properties of ionic liquids and IoNanofluids of imidazolium and pyrrolidinium liquids," Journal of Chemical \& Engineering Data, vol. 55, no. 2, pp. 653-661, 2010.

[31] B. Jóźwiak, G. Dzido, E. Zorębski et al., "Remarkable thermal conductivity enhancement in carbon-based ionanofluids: effect of nanoparticle morphology," ACS Applied Materials \& Interfaces, vol. 12, no. 34, pp. 38113-38123, 2020.

[32] E. I. Chereches and A. A. Minea, "A study on few thermophysical properties of ionanofluids," in Proceedings of the The International Conference on Innovative Applied Energy (IAPE'19), Oxford, UK, March, 2019.

[33] K. Oster, J. Jacquemin, C. Hardacre, A. Ribeiro, and A. Elsinawi, "Ionic liquid-based nanofluids (ionanofluids) for thermal applications: an experimental thermophysical characterization," Pure and Applied Chemistry, vol. 91, no. $8,2019$.

[34] A. Bejan, Convection Heat Transfer, John Wiley \& Sons, Hoboken, NJ, USA, 2013.

[35] S. V. Patankar, Numerical Heat Transfer and Fluid Flow, Hemisphere Publishing Corporation, Taylor and Francis Group, NewYork, NY, USA, 1980.

[36] H. F. Oztop and E. Abu-Nada, "Numerical study of natural convection in partially heated rectangular enclosures filled with nanofluids," International Journal of Heat and Fluid Flow, vol. 29, no. 5, pp. 1326-1336, 2008.

[37] T. C. Paul, A. Morshed, E. B. Fox, A. E. Visser, N. J. Bridges, and J. A. Khan, "Buoyancy driven heat transfer behavior of $\left[\mathrm{C}_{4} \mathrm{mim}\right]\left[\mathrm{NTf}_{2}\right]$ ionic liquid. an experimental study," Applied Thermal Engineering, vol. 66, no. 1-2, pp. 534-540, 2014.

[38] P. Ternik and R. Rudolf, "Conduction and convection heat transfer characteristics of water-based au nanofluids in a square cavity with differentially heated side walls subjected to constant temperatures," Thermal Science, vol. 18, no. 1, pp. 189-200, 2014.

[39] P. Ternik, "Conduction and convection heat transfer characteristics of water-Au nanofluid in a cubic enclosure with differentially heated side walls," International Journal of Heat and Mass Transfer, vol. 80, pp. 368-375, 2015.

[40] P. Ternik and R. Rudolf, "Numerical analysis of continuous casting of NiTi shape memory alloy," International Journal of Simulation Modelling, vol. 15, no. 3, pp. 522-531, 2016.

[41] J. P. Van Doormaal and G. D. Raithby, "Enhancements of the simple method for predicting incompressible fluid flows," Numerical Heat Transfer, vol. 7, no. 2, pp. 147-163, 1984. 